CLINICAL STUDY

\title{
Tissue inhibitor of metalloproteinase-1 predicts adiposity in humans
}

Susan Kralisch, Matthias Bluher, Anke Tonjes, Ulrike Lossner, Ralf Paschke, Michael Stumvoll and Mathias Fasshauer

Department of Internal Medicine III, University of Leipzig, Ph.-Rosenthal-Str. 27, 04103 Leipzig, Germany

(Correspondence should be addressed to M Fasshauer; Email: mathias.fasshauer@medizin.uni-leipzig.de)

\begin{abstract}
Objective: Tissue inhibitor of metalloproteinase (TIMP)-1 is upregulated in fat of obese rodents and promotes adipose tissue development in these animals. However, it is unclear whether TIMP-1 independently predicts adiposity in humans and whether serum levels are increased in s.c. and visceral obesity.

Design: Twenty-four lean, 16 s.c. obese, and 20 visceral obese subjects were studied.

Methods: Plasma TIMP-1 concentrations were quantified using ELISAs and correlated to clinical parameters.

Results: Plasma TIMP-1 levels were significantly different between lean $(156 \pm 42 \mu \mathrm{g} / \mathrm{l})$, s.c. obese $(186 \pm 52 \mu \mathrm{g} / \mathrm{l})$, and visceral obese $(198 \pm 42 \mu \mathrm{g} / \mathrm{l})$ subjects $(P<0.01)$. Furthermore, TIMP-1 correlated positively with body mass index (BMI), waist-to-hip ratio (WHR), \% body fat, fasting insulin, free fatty acids, cholesterol, leptin, interleukin-6, and negatively with adiponectin $(P<0.05)$. Moreover, TIMP-1 serum levels predicted \% body fat but not WHR independent of age, sex, and plasma insulin.

Conclusions: We demonstrate that increased TIMP-1 serum levels are found with increased adiposity in humans.
\end{abstract}

European Journal of Endocrinology 156 257-261

\section{Introduction}

In Western societies, obesity is a rapidly growing nutritional disorder (1). It is characterized by excessive accumulation of adipose tissue with both hyperplasia and hypertrophy of fat cells (2). Neovascularization of expanding adipose tissue is a critical step to maintain proper function (3). Recent studies suggest that the growth of new vessels depends on dynamic changes of cell-matrix interactions, as well as extensive extracellular matrix (ECM) remodeling (4). In this context, several members of the matrix metalloproteinase (MMP) family and the tissue inhibitors of MMPs (TIMPs) have been suggested as primary mediators of ECM remodeling (4). MMPs are a family of more than 20 neutral endopeptidases, whereas TIMPs comprise a family of four members (4). MMPs cleave not only ECM components but also several non-ECM proteins, including cytokines, adhesion molecules, and proteinase inhibitors (4). By interaction with TIMP family members, MMP activity is inhibited (4). In recent years, the potential contribution of MMPs and TIMPs to obesity-related adipose tissue enlargement has been better understood in rodents. Here, TIMP-1 is an interesting novel candidate adipokine-promoting expansion of adipose tissue for several reasons. First, two independent reports have demonstrated significant upregulation of adipose tissue TIMP-1 mRNA expression in mice with genetically based or diet-induced obesity $(5,6)$. Furthermore, transgenic overexpression of TIMP-1 increased the rate of adipocyte differentiation in vivo (7). In agreement with these results, the addition of recombinant TIMP-1 to 3T3-L1 cells dramatically accelerated lipid accumulation during adipocyte differentiation in vitro (7). Mice lacking TIMP-1 were protected from nutritionally induced obesity which is also consistent with a fatpromoting effect of this adipokine (8).

Moreover, we have recently demonstrated that the proinflammatory adipokines interleukin (IL)-6 and tumor necrosis factor (TNF)- $\alpha$, as well as the $\beta$-adrenergic agonist isoproterenol, are potent stimulators of adipocyte TIMP-1 synthesis $(9,10)$. Taking these studies into consideration, TIMP-1 appears as a novel adipokine-promoting adipose tissue development in rodents when weight is gained. However, in contrast to the data in rodents, little is known on TIMP-1 serum levels in human obesity. In the present study, we, therefore, examined the levels of TIMP-1 in lean, s.c. obese, and visceral obese patients. We demonstrate for the first time that TIMP-1 serum concentrations are 
significantly different in these groups. Furthermore, we show for the first time that TIMP-1 is correlated to adiposity, but not to waist-to-hip ratio (WHR) and body mass index (BMI) independent of age, sex, and plasma insulin.

\section{Subjects and Methods}

\section{Subjects}

We recruited 60 Caucasian men $(n=32)$ and women $(n=28)$ with 24 patients being lean $\left(\mathrm{BMI}<27 \mathrm{~kg} / \mathrm{m}^{2}\right)$, 16 patients showing s.c. obesity $\left(\mathrm{BMI}>27 \mathrm{~kg} / \mathrm{m}^{2}\right.$, CT-ratio $<0.40$ ), and 20 patients having visceral obesity $\left(\mathrm{BMI}>27 \mathrm{~kg} / \mathrm{m}^{2}\right.$, CT-ratio $\left.>0.40\right)$. BMI was calculated as weight divided by squared height. Visceral fat area and the relative ratio of intraabdominal visceral fat to the s.c. fat area were calculated using CT scans at the level of L4-L5 as described recently (11). Waist and hip circumferences were determined and WHR was calculated. \% body fat was measured by dual X-ray absorptiometry. All subjects did not have changes of body weight of more than $2 \%$ for at least 3 months before blood samples were taken. The age ranged from 22 to 87 years and BMI from 21.8 to $45.8 \mathrm{~kg} / \mathrm{m}^{2}$. Fourteen patients had type 2 diabetes mellitus. Patients with severe conditions such as generalized inflammation or end stage malignant diseases were excluded from the study. The study was approved by the local Ethics Committee and all subjects gave written informed consent before taking part in the study.

\begin{abstract}
Assays
After an overnight fast, blood samples were taken. Plasma insulin was measured with a two-site chemiluminescent enzyme immunometric assay for the Immulite automated analyzer (Diagnostic Products, Los Angeles, CA, USA). Leptin (Linco Research, St Charles, MO, USA), adiponectin (Linco Research, St Charles, MO, USA), IL-6 (R\&D Systems, Oxford, UK), and TIMP-1 (GE Healthcare, Munich, Germany) serum levels were determined with commercially available ELISAs according to the manufacturer's instructions. For the TIMP-1 ELISA, the withinassay variation coefficient was between 8.9 and $11.4 \%$. The between-assay variation coefficient ranged from 12.4 to $15.2 \%$.
\end{abstract}

\section{Oral glucose tolerance test}

Oral glucose tolerance tests were performed according to the criteria of the American Diabetes Association to distinguish non-diabetic from diabetic subjects. There were five patients with diabetes in the group of s.c. obese patients. Furthermore, nine patients of the visceral obese group had diabetes mellitus.

\section{Euglycemic-hyperinsulinemic glucose clamp}

Insulin sensitivity was assessed with the euglycemichyperinsulinemic clamp method in a subset of 50 patients (19 lean, 14 s.c. obese, and 17 visceral obese) as described recently (11).

\section{Statistical analysis}

SPSS statistical software version 11.5 (SPSS, Chicago, IL, USA) was used for all analyses. Distribution was tested for normality using Shapiro-Wilk $W$-test. For all analyses, non-normally distributed parameters were logarithmically transformed to approximate a normal distribution. Differences in TIMP-1 serum levels between lean, s.c. obese, and visceral obese patients were assessed by Kruskal-Wallis test. Post hoc analysis was performed using Tukey test. Correlations were performed using the Spearman rank correlation method. To adjust the effects of covariates and identify independent relationships, multivariate linear regression analyses were performed. A $P$ value of $<0.05$ was considered as statistically significant in all analyses.

\section{Results}

\section{Effect of s.c. and visceral obesity on TIMP-1 serum levels}

Mean \pm s.D. plasma TIMP-1 was $178 \pm 48 \mu \mathrm{g} / \mathrm{l}$ (range 91-304) in the total sample. Clinical characteristics of the study subjects and the subgroups studied (lean, s.c. obese, and visceral obese) are shown in Table 1. Mean plasma TIMP-1 levels were significantly different between lean $(156 \pm 42 \mu \mathrm{g} / \mathrm{l})$, s.c. obese $(186 \pm 52 \mu \mathrm{g} / \mathrm{l})$, and visceral obese $(198 \pm 42 \mu \mathrm{g} / \mathrm{l})$ subjects $(P<0.01)$ as assessed by Kruskal-Wallis test (Fig. 1). TIMP-1 levels were significantly higher in visceral obese when compared with lean subjects as assessed by post hoc analysis using Tukey test $(P<0.01$; Fig. 1). In contrast, differences between lean and s.c. obese, as well as between s.c. obese and visceral obese, subjects did not reach statistical significance in the post hoc analysis $(P>0.05$; Fig. 1). TIMP-1 serum levels were not different between diabetic and non-diabetic patients (data not shown).

\section{Univariate correlations}

Serum TIMP-1 levels positively correlated with BMI, WHR, \% body fat, fasting insulin, FFA, cholesterol, leptin, and IL-6 $(P<0.05$; Table 2). Furthermore, serum TIMP-1 was negatively correlated with adiponectin $(P<0.05$; Table 2$)$. In a subset of patients $(n=50)$, no correlation between glucose infusion rate during a euglycemic-hyperinsulinemic clamp and 
Table 1 Baseline characteristics of the study population.

\begin{tabular}{lcccc}
\hline & All subjects & Lean & s.c. Obese & Visceral obese \\
\hline$N$ & 60 & 24 & 16 & 20 \\
TIMP-1 $(\mu \mathrm{g} / \mathrm{l})$ & $178 \pm 48$ & $156 \pm 42$ & $186 \pm 52$ & $198 \pm 42$ \\
Age (years) & $58 \pm 16$ & $51 \pm 19$ & $64 \pm 9$ & $62 \pm 12$ \\
Sex $(\mathrm{m} / \mathrm{f})$ & $32 / 28$ & $16 / 8$ & $6 / 10$ & $10 / 10$ \\
BMI $\left(\mathrm{kg} / \mathrm{m}^{2}\right)$ & $30 \pm 6$ & $24 \pm 1$ & $35 \pm 5$ & $32 \pm 4$ \\
WHR & $1.01 \pm 0.19$ & $0.84 \pm 0.13$ & $1.14 \pm 0.17$ & $1.10 \pm 0.10$ \\
$\%$ Body fat & $31 \pm 10$ & $23 \pm 3$ & $51 \pm 10$ & $33 \pm 6$ \\
Fasting glucose $(\mathrm{mmol} / \mathrm{l})$ & $5.82 \pm 1.09$ & $5.38 \pm 0.67$ & $32 \pm 16$ & $6.24 \pm 1.14$ \\
Fasting insulin (pmol/l) & $148 \pm 137$ & $0.38 \pm 0.20$ & $0.66 \pm 0.40$ & $237 \pm 118$ \\
FFA (mmol/l) & $0.58 \pm 0.32$ & $4.91 \pm 0.84$ & $6.20 \pm 0.80$ & $0.76 \pm 0.23$ \\
Cholesterol (mmol/l) & $5.24 \pm 0.84$ & $6 \pm 4$ & $28 \pm 13$ & $5.67 \pm 0.70$ \\
Leptin $(\mu \mathrm{g} / \mathrm{l})$ & $20 \pm 16$ & $10.67 \pm 5.05$ & $30 \pm 14$ \\
Adiponectin $(\mathrm{mg} / \mathrm{l})$ & $7.12 \pm 4.86$ & $0.96 \pm 0.71$ & $3.22 \pm 1.28$ & $3.26 \pm 2.55$ \\
IL-6 (ng/l) & $3.00 \pm 2.27$ & & $5.29 \pm 1.78$ \\
\hline
\end{tabular}

Values for mean \pm s.D. are shown.

TIMP-1 serum levels was observed $(r=0.11, P=0.44 ; \quad$ Discussion

data not shown).

\section{Multivariate correlations}

Adiposity as determined by dual X-ray absorptiometry and calculated as \% body fat remained significantly and positively correlated with serum TIMP-1 concentrations after adjusting for age and sex (Table 3). This correlation persisted after additional adjustment for plasma insulin (Table 3). In contrast, correlations between WHR or BMI and serum TIMP-1 levels did not remain significant after adjustment for age and sex (data not shown).

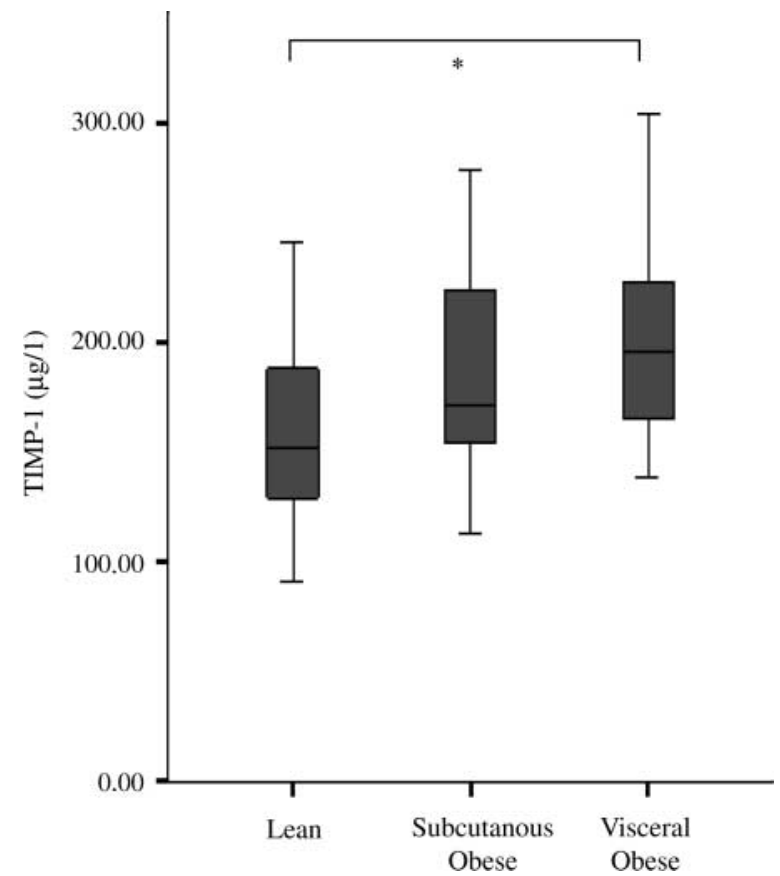

Figure 1 Boxplot graphs of TIMP-1 serum concentrations in lean, s.c. obese, and visceral obese subjects. *Denotes $P<0.01$ comparing lean with visceral obese subjects as assessed by post hoc Tukey test.
In the present study, we demonstrate for the first time that a relationship between increased adiposity determined by dual X-ray absorptiometry and high TIMP-1 serum concentrations exists independent of age, sex, and plasma insulin levels. In contrast, TIMP-1 serum levels do not correlate to insulin

Table 2 Univariate correlations with serum TIMP-1 concentrations.

\begin{tabular}{lcc}
\hline & $\boldsymbol{r}$ & $\boldsymbol{P}$ \\
\hline BMI & 0.353 & 0.006 \\
WHR & 0.265 & 0.041 \\
\% Body fat & 0.408 & 0.001 \\
Fasting glucose & 0.106 & 0.421 \\
Fasting insulin & 0.304 & 0.018 \\
FFA & 0.367 & 0.004 \\
Cholesterol & 0.400 & 0.002 \\
Leptin & 0.275 & 0.039 \\
Adiponectin & -0.321 & 0.015 \\
IL-6 & 0.390 & 0.003 \\
\hline
\end{tabular}

Table 3 Correlation between \% body fat (dependent variable) and serum TIMP-1 concentrations (model 1 ) adjusted for age (model 2 ), age and sex (model 3), as well as age, sex, and plasma insulin (model 4).

\begin{tabular}{llcc}
\hline Model & $\begin{array}{l}\text { Independent } \\
\text { variable }\end{array}$ & $\boldsymbol{\beta}$-coefficient & $\boldsymbol{P}$ value \\
\hline Model 1 & TIMP-1 & 0.425 & 0.001 \\
Model 2 & TIMP-1 & 0.376 & 0.003 \\
& Age & 0.180 & 0.146 \\
Model 3 & TIMP-1 & 0.354 & 0.005 \\
& Age & 0.151 & 0.225 \\
Model 4 & Sex & -0.169 & 0.167 \\
& TIMP-1 & 0.261 & 0.026 \\
& Age & 0.017 & 0.883 \\
& Sex & -0.143 & 0.198 \\
& Insulin & 0.424 & 0.001 \\
\hline
\end{tabular}

Dependent variable: \% body fat. 
sensitivity as assessed by the euglycemic-hyperinsulinemic clamp method. Taking these results into consideration, it is likely that TIMP-1 is related to human adiposity but not to insulin resistance. Animal experiments suggest that TIMP-1 not only increases when weight is gained but might also actively maintain fat mass $(7,8)$. Therefore, transgenic overexpression of TIMP-1 stimulates adipocyte differentiation in vivo and in vitro (7), whereas TIMP-1 knockout mice are protected from obesity (8). The mechanisms by which TIMP-1 promotes adipose tissue mass accumulation are not completely clear. Recent studies show that TIMP-1 but not TIMP-2 has growth-promoting activity in a wide range of cells (12). Furthermore, in a second independent study, significant suppression of apoptosis in B cells after TIMP-1 but not TIMP-2 treatment is demonstrated (13). Interestingly, both studies suggest that the effects of TIMP-1 on proliferation and apoptosis are not due to metalloproteinase inhibition $(12,13)$. These findings are of special interest since pharmacological inhibition of MMPs, in contrast to TIMP-1, leads to impaired adipogenesis in vitro and in vivo $(5,6,14$, 15). Taking these studies into account, TIMP-1 appears to maintain fat mass independent of MMP inhibition in rodents possibly via increased proliferation and/or decreased apoptosis. However, it has to be pointed out that direct evidence in humans for a role of TIMP-1 in adipose tissue accumulation has not been presented so far. Clearly, more work is needed to more thoroughly understand the mechanisms by which TIMP-1 promotes fat accumulation in rodents and potentially humans. We present first evidence that TIMP-1 serum levels in humans are significantly different in lean, s.c. obese, and visceral obese subjects with highest levels seen in visceral obesity. In recent years, various studies have examined the relationship between total, s.c., and visceral adipose tissue mass on one hand and insulin resistance, type 2 diabetes mellitus, and cardiovascular disease on the other hand (16-20). Despite the fact that the visceral adipose tissue depot is much smaller when compared with s.c. fat, various investigators have shown convincingly that only visceral adipose tissue mass but not s.c. or total fat mass is significantly correlated with impaired glucose tolerance, cardiovascular events, and adipokine dysregulation (16-20). In agreement with these published findings, in our study, visceral obese when compared with s.c. obese subjects show significantly increased IL-6 levels whereas adiponectin is decreased. Whether increased serum levels of TIMP-1 seen in visceral obesity might contribute to preferential fat accumulation in the visceral adipose depot has to be determined in future studies. Taken together, we demonstrate that TIMP-1 serum levels are an independent predictor of adiposity in humans with highest levels seen in visceral obesity.

\section{Acknowledgements}

This study was supported by a grant from the Deutsche Forschungsgemeinschaft (DFG), KFO 152: 'Atherobesity', project FA476/4-1 (TP 4) to MF, project BL833/ 1-1 (TP3) to MB, and the Deutsche Diabetes Gesellschaft to SK.

\section{References}

1 Fasshauer $M$ \& Paschke R. Regulation of adipocytokines and insulin resistance. Diabetologia 200346 1594-1603.

2 Kralisch S, Klein J, Bluher M, Paschke R, Stumvoll M \& Fasshauer M. Therapeutic perspectives of adipocytokines. Expert Opinion on Pharmacotherapy 20056 863-872.

3 Crandall DL, Hausman GJ \& Kral JG. A review of the microcirculation of adipose tissue: anatomic, metabolic, and angiogenic perspectives. Microcirculation 19974 211-232.

4 Beaudeux JL, Giral P, Bruckert E, Foglietti MJ \& Chapman MJ. Matrixmetalloproteinases, inflammation and atherosclerosis: therapeutic perspectives. Clinical and Chemical Laboratory Medicine 200442 121-131.

5 Maquoi E, Munaut C, Colige A, Collen D \& Lijnen HR. Modulation of adipose tissue expression of murine matrix metalloproteinases and their tissue inhibitors with obesity. Diabetes 200251 1093-1101.

6 Chavey C, Mari B, Monthouel MN, Bonnafous S, Anglard P, Van Obberghen E \& Tartare-Deckert S. Matrix metalloproteinases are differentially expressed in adipose tissue during obesity and modulate adipocyte differentiation. Journal of Biological Chemistry 2003278 11888-11896.

7 Alexander CM, Selvarajan S, Mudgett J \& Werb Z. Stromelysin-1 regulates adipogenesis during mammary gland involution. Journal of Cell Biology 2001152 693-703.

8 Lijnen HR, Demeulemeester D, Van Hoef B, Collen D \& Maquoi E. Deficiency of tissue inhibitor of matrix metalloproteinase-1 (TIMP1) impairs nutritionally induced obesity in mice. Thrombosis and Haemostasis $200389249-255$.

9 Kralisch S, Klein J, Lossner U, Bluher M, Paschke R, Stumvoll M \& Fasshauer M. Proinflammatory adipocytokines induce TIMP-1 expression in 3T3-L1 adipocytes. FEBS Letters $2005 \mathbf{5 7 9}$ 6417-6422.

10 Kralisch S, Lossner U, Bluher M, Paschke R, Stumvoll M \& Fasshauer M. TIMP-1 expression and secretion are induced by $\beta$-adrenergic stimulation in 3T3-L1 adipocytes. Journal of Endocrinology 2006189 665-670.

11 Berndt J, Kloting N, Kralisch S, Kovacs P, Fasshauer M, Schon MR, Stumvoll M \& Bluher M. Plasma visfatin concentrations and fat depot-specific mRNA expression in humans. Diabetes $2005 \mathbf{5 4}$ 2911-2916.

12 Hayakawa T, Yamashita K, Tanzawa K, Uchijima E \& Iwata K. Growth-promoting activity of tissue inhibitor of metalloproteinases-1 (TIMP-1) for a wide range of cells. A possible new growth factor in serum. FEBS Letters 1992298 29-32.

13 Guedez L, Stetler-Stevenson WG, Wolff L, Wang J, Fukushima P, Mansoor A \& Stetler-Stevenson M. In vitro suppression of programmed cell death of $\mathrm{B}$ cells by tissue inhibitor of metalloproteinases-1. Journal of Clinical Investigation $1998 \mathbf{1 0 2}$ 2002-2010.

14 Demeulemeester D, Collen D \& Lijnen HR. Effect of matrix metalloproteinase inhibition on adipose tissue development. Biochemical and Biophysical Research Communications 2005329 $105-110$.

15 Lijnen HR, Maquoi E, Hansen LB, Van Hoef B, Frederix L \& Collen D. Matrix metalloproteinase inhibition impairs adipose tissue development in mice. Arteriosclerosis, Thrombosis, and Vascular Biology 200222 374-379. 
16 Banerji MA, Faridi N, Atluri R, Chaiken RL \& Lebovitz HE. Body composition, visceral fat, leptin, and insulin resistance in Asian Indian men. Journal of Clinical Endocrinology and Metabolism 1999 84 137-144.

17 Boyko EJ, Fujimoto WY, Leonetti DL \& Newell-Morris L. Visceral adiposity and risk of type 2 diabetes: a prospective study among Japanese Americans. Diabetes Care 200023 465-471.

18 Lemieux S, Prud'homme D, Nadeau A, Tremblay A, Bouchard C \& Despres JP. Seven-year changes in body fat and visceral adipose tissue in women. Association with indexes of plasma glucoseinsulin homeostasis. Diabetes Care 199619 983-991.

19 Fujimoto WY, Bergstrom RW, Boyko EJ, Chen KW, Leonetti DL, Newell-Morris L, Shofer JB \& Wahl PW. Visceral adiposity and incident coronary heart disease in Japanese-American men. The 10-year follow-up results of the Seattle Japanese-American Community Diabetes Study. Diabetes Care 199922 1808-1812.

20 Pouliot MC, Despres JP, Nadeau A, Moorjani S, Prud'homme D, Lupien PJ, Tremblay A \& Bouchard C. Visceral obesity in men. Associations with glucose tolerance, plasma insulin, and lipoprotein levels. Diabetes 199241 826-834.

Received 11 September 2006

Accepted 2 November 2006 